\title{
Trends in processing and manufacturing that will affect implementation of the Chemical Weapons Convention*
}

\author{
George W. Parshall \\ E. I. DuPont de Nemours and Company (retired), 2504 Delaware Ave., Wilmington, \\ DE 19806, USA
}

\begin{abstract}
Several new developments in synthesis science and manufacturing technology may affect the task of implementing the Chemical Weapons Convention (CWC) constraints on the production of toxic agents for military or terrorist purposes. The combination of automated synthesis methods and high-throughput screening protocols could potentially yield new toxic agents not specifically proscribed by the CWC, but such approaches are unlikely to seriously impact the work of the Organisation for the Prohibition of Chemical Weapons $(\mathrm{OPCW})$ in the near future. On the other hand, new developments in manufacturing may have a serious impact on the work of the OPCW inspectors. The wide use of versatile, multipurpose production facilities in making fine chemicals complicates the task of discerning whether a particular facility is used only for nonprohibited purposes under the CWC. New catalytic processes and automated process control permit production of toxic chemicals with fewer emissions that contaminate the environment and might provide clues to the nature of the processes being conducted. Tiny microreactors operated continuously under computer control can produce significant quantities of toxic chemicals (including CWC-scheduled compounds) with a very small "footprint" within a larger production facility. These technical developments together with the dispersal of chemical production facilities and skills may seriously complicate the tasks of the OPCW inspectors.
\end{abstract}

\section{INTRODUCTION}

Many new developments in science and technology may affect the task of implementing CWC constraints on production of toxic agents for military or terrorist purposes [1]. Improvements in analytical instrumentation and methodology should facilitate detection of illicit production of chemical warfare agents. On the other hand, new synthesis methods and manufacturing technology may make it easier to make chemical weapons surreptitiously. These latter technological trends are surveyed in this paper. In addition to technological change, the chemical industry is undergoing major changes in the ways that it conducts its business. Some of the business aspects may outweigh technological change in their impact on enforcing the CWC.

\section{SCIENTIFIC ADVANCES}

Major changes have occurred in the way that research is conducted at the interface between chemistry and biology. The availability of powerful computers has enabled new ways to search for biologically active chemicals such as pharmaceuticals, agrochemicals, and, unfortunately, toxic agents.

*Lecture presented at the IUPAC Workshop, Impact of Scientific Developments on the Chemical Weapons Convention, Bergen, Norway, 30 June-3 July 2002. Other presentations are published in this issue, pp. 2229-2322. 


\section{Combinatorial synthesis}

Robotic laboratory tools permit synthesis of hundreds or thousands of organic compounds by a single well-equipped laboratory. New high-throughput screening techniques permit the biologist to test minute quantities of new compounds as fast as they can be synthesized. The combination of these techniques greatly accelerates the search for new forms of physiological activity as well as optimizing structure-activity relationships once a new lead is discovered. These methods are having a major impact on research in the pharmaceutical and agrochemical businesses, as described by Prof. Bradley and Dr. Müller in this workshop.

A key factor in the development of these new laboratory tools is the availability of powerful, inexpensive computers and sophisticated software. The computer plays a role not only in laboratory manipulations but also in analysis of the enormous mass of data generated in making and testing thousands of compounds. Indeed, the laboratory effort might be wasted were it not for automated analysis of experimental data (bioinformatics). Analysis of the voluminous data depends on specialized programs to detect new forms of biological activity as well as to optimize desired physiological properties. While these methods have been applied primarily to discovery of new drugs and pesticides, they also could in theory impact chemical weapons issues in two ways: (1) New toxic mechanisms may be detected during random screening for other properties; and (2) A rogue nation with moderate scientific infrastructure could screen specifically for new toxic agents. Dr. Wheelis discussed the ramifications of these possibilities in the context of the CWC and the Biological Weapons Convention.

\section{Biological syntheses}

Genetic engineering of microorganisms enables the synthesis of many types of organic chemicals from simple starting materials such as corn syrup. An example of such a process nearing commercial production is the manufacture of 1,3-propanediol (a polymer intermediate) by bioprocessing of corn sugar. Similarly, a lactic acid-based polymer is already being produced from corn sugar on a pilot scale and a large commercial polylactic acid facility is being constructed [2]. Similar methodologies might be adapted to the biosynthesis of intermediates for producing chemical agents. These methods may also be adaptable to the efficient production of peptide-based toxins such as ricin.

\section{New toxins}

Both empirical screening and surveys of the literature can potentially uncover new toxins that operate through physiological mechanisms different from those involved in traditional chemical warfare agents. New mechanisms can lead to agents that are more difficult to detect and treat [3]. Toxins based on peptides or pseudopeptides based on unnatural amino acids may emerge from screening conducted for peaceful purposes.

\section{TECHNOLOGICAL ADVANCES}

Computer automation coupled with new catalytic processes have changed many production processes used for the manufacture of organic chemicals. Some of these changes could have a major impact on the work of the OPCW by making it more difficult to detect the production of lethal chemicals.

\section{Automated process control}

Perhaps the greatest change in the processing and manufacture of chemicals is the use of computers to control the equipment in which chemicals are reacted and purified. Automated control has made production processes safer and more efficient. In many instances, it has reduced the level of skill and expe- 
rience needed to carry out routine production operations and has made unattended operation feasible. As applied to clandestine production of chemical agents, it has the potential to reduce the number of personnel involved, to make the handling of lethal chemicals safer, and to reduce or eliminate emissions that might call attention to illicit production.

\section{Mini/micro reactors}

As described in the paper by Dr. Löwe, collections of tiny reactors made by techniques borrowed from the electronics industry can operate continuously and produce significant quantities of chemicals. One such process is approaching commercial use in the pharmaceuticals industry. Another virtue cited for the microreactors is increased safety in the production of toxic chemicals. The production of lethal chemicals such as hydrogen cyanide (HCN), methyl isocyanate (MIC), and phosgene has been demonstrated in such reactors [4]. In the wrong hands, the small size and efficiency of such reactors could facilitate the clandestine manufacture of chemical agents.

\section{New catalysts}

In the field of heterogeneous catalysis, new, recently commercialized processes could enable the manufacture of toxic chemicals (including Schedule 3 chemicals) from intermediates that are not monitored under current CWC inspection regimes. One example is the production of MIC from readily available $N$-methylformamide. MIC, the toxic agent involved in the Bhopal tragedy in 1984 , is usually made by reaction of phosgene (a CWC Schedule 3 chemical) with monomethylamine:

$$
\mathrm{COCl}_{2}+3 \mathrm{MeNH}_{2} \rightarrow \mathrm{MeN}=\mathrm{C}=\mathrm{O}+2 \mathrm{MeNH}_{3} \mathrm{Cl}
$$

Following the Bhopal incident, the DuPont Company sought a just-in-time production process for MIC so that it could be used in pesticide manufacture without storing large quantities of this highly toxic chemical. Oxidative dehydrogenation of $N$-methylformamide over a specially tailored silver catalyst provided the desired process characteristics [5]:

$$
\mathrm{MeNHCHO}+\text { air } \rightarrow \mathrm{MeN}=\mathrm{C}=\mathrm{O}+\mathrm{H}_{2} \mathrm{O}
$$

This process has been in commercial use for several years. It is operated at an agrochemicals production site and is closely coupled to the processes that consume MIC so that little MIC is present on site at any time. DuPont uses a similar strategy for its $\mathrm{HCN}$-based process for making adiponitrile, a nylon intermediate. The catalytic production of $\mathrm{HCN}$ is so closely coupled to the processes that use the HCN that no more than a 15-min inventory is present. This just-in-time production strategy is being adopted at many chemical plants to enhance safety, but it has the further advantage of making toxic chemicals unavailable for terrorists.

New heterogeneous catalysts have also made the production of phosgene more efficient in that fewer byproducts are emitted. With the usual carbon catalysts for chlorination of carbon monoxide, the carcinogen carbon tetrachloride is produced in sufficient quantities as to be an air emissions problem.

$$
\mathrm{CO}+\mathrm{Cl}_{2} \rightarrow \mathrm{COCl}_{2}\left(+\mathrm{CCl}_{4}\right)
$$

However, with a special, high-surface-area carbon catalyst, the coproduction of $\mathrm{CCl}_{4}$ is almost negligible [6]. DuPont uses this new catalyst in its own production of phosgene and has also licensed the technology to other producers.

Thionyl chloride, a CWC Schedule 3 precursor, has also become easier to produce through the use of a new silicon carbide catalyst [7]. While the chlorination of sulfur dioxide at low temperatures cleanly gives sulfuryl chloride $\left(\mathrm{SO}_{2} \mathrm{Cl}_{2}\right)$, chlorination at $300{ }^{\circ} \mathrm{C}$ produces $\mathrm{SOCl}_{2}$ in high yield.

The new catalytic processes for phosgene and thionyl chloride production are not only cleaner than their predecessors, but they are also more productive. In commercial practice, the new phosgene 
synthesis catalyst has led to $20 \%$ greater production from existing facilities. For a rogue nation or a group seeking to produce phosgene for illicit purposes, substitution of the new catalyst in an existing agrochemical facility could yield an abundant supply of undeclared chemical agent.

Prof. Beletskaya described advances in homogeneous catalysis that could facilitate the manufacture of both commodity and fine chemicals. She described new water-soluble catalysts that can facilitate synthesis of a variety of organic chemicals in processes that minimize solvent emissions. The impact of these developments on CWC issues remains to be seen.

\section{CHEMICAL INDUSTRY CHANGES}

The global chemical industry has undergone dramatic changes in the way it conducts its business. Some of the changes in business practices may be more important than technological advances in terms of their impact on implementing the CWC.

\section{Globalization}

The worldwide chemical industry has experienced many changes in how and where it manufactures chemicals [8]. Economic factors have encouraged the production of many polymers and commodity chemicals in production facilities large enough to supply the needs of an entire region. So-called worldscale production facilities are often built in developed countries where large markets already exist. An important recent countertrend is shifting the production of commodity chemicals such as polyolefins and methanol close to sources of raw materials. For example, these kinds of chemicals are now produced on a massive scale in the Persian Gulf region, which offers abundant cheap petroleum and natural gas as feedstocks. These world-scale plants are being followed by facilities to make smaller-scale specialty chemicals such as agrochemicals.

\section{Dispersal of specialty chemicals production}

Many less-developed countries have encouraged the domestic production of agrochemicals and pharmaceuticals by imposing high tariffs on imported materials and by relaxing enforcement of patent regulations. Contract manufacture of pharmaceutical intermediates has spread to a few developing countries to take advantage of lower costs for skilled labor. The net result has been to create an industrial base that, without adequate oversight, could carry out surreptitious manufacture of chemical agents.

\section{Dispersal of chemical weapons production skills}

The disavowal of chemical weapons by the countries of the former Soviet Union has had an ironic effect: many of the workers who once produced chemical agents are now underemployed and available for hire [9]. Such individuals could find employment in the development of agent production in the socalled rogue nations. They would be particularly valuable to a covert chemical weapons program because of their skills for integrating toxic chemicals into delivery devices. While the skills of other chemical production workers could be transferred to manufacture of toxic agents, the skills for creating actual weapons are quite specialized.

\section{Marketing through digital exchanges}

Another trend is the increase in sales of chemicals through automated exchanges that bring together buyers and sellers via the Internet. An increasing number of chemical intermediates, including some materials for making chemical agents, are traded in this way. This trend could have either positive or negative effects in controlling the production of potential chemical agents. Without adequate controls, 
this system could make key intermediates easily available to terror groups. On the other hand, proper oversight of purchases could detect clandestine chemical agent production just as is done currently for detecting narcotics manufacture [10].

\section{CONCLUSIONS}

The trends in chemical manufacturing that are most likely to influence the task of OPCW inspectors are:

- developments in catalysis and reactor technology that could make it easier to produce chemical warfare agents in ways that are difficult to detect and

- $\quad$ global dispersal of fine chemicals production in multipurpose facilities that will be difficult to monitor effectively.

Countering these trends will require inspectors who are broadly knowledgeable about modern manufacturing practices and up to date on new process technology. The role of the CWC States Parties in policing illegal production of potential chemical agents will be even more important.

\section{REFERENCES}

1. G. W. Parshall. "Scientific and technical developments and the CWC". In The Chemical Weapons Convention - Implementation Challenges and Solutions, Jonathan B. Tucker (Ed.), Monterey Institute for International Studies, Monterey, CA, April 2001.

2. A. M. Thayer. "Biocatalysis", Chem. Eng. News 79 (21), 27-34 (2001).

3. M. Wheelis. "Biotechnology and biochemical weapons", Nonproliferation Review 9 (1), 48-53 (2002).

4. J. J. Lerou, cited in N. P. Chopey with G. Ondrey and G. Parkinson, "Microreactors find new niches", Chem. Eng. (March 1997) pp. 30-33.

5. V. N. M. Rao and G. E. Heinsohn. "Multistage process with adiabatic reactors for the preparation of isocyanates", U.S. Patent 4,537,726 (1985).

6. W. Cicha and L. E. Manzer. "Phosgene manufacturing process", U.S. Patent 6,022,993 (2000).

7. W. Cicha and L. E. Manzer. "Preparation of sulphuryl chloride and/or thionyl chloride", U.S. Patent 5,759,508 (1998).

8. C. A. Tolman and G. W. Parshall. "Fifty year trends in the chemical industry", J. Chem. Educ. 76 (2), 177-189 (1999).

9. S. Ben Ouaghram. "Conversion of Russian chemical weapons production facilities", Nonproliferation Review 7 (2), 44-62 (2000).

10. J. M. Tour. "Do-it-yourself chemical weapons", Chem. Eng. News 78 (28), $42-45$ (2000). 